8-1-2019

\title{
Conocimiento, actitudes y prácticas sobre el Zika: Implicancias programaticas para la prevencion del Zika en Guatemala
}

Breakthrough RESEARCH

Follow this and additional works at: https://knowledgecommons.popcouncil.org/departments_sbsr-pgy How does access to this work benefit you? Let us know!

\section{Recommended Citation}

Breakthrough RESEARCH. 2019. “Conocimiento, actitudes y prácticas sobre el Zika: Implicancias programaticas para la prevencion del Zika en Guatemala," Breakthrough Research Consortium Programmatic Research Brief. Washington, DC: Population Council. 


\section{Antecedentes}

El primer brote de Zika registrado en las Américas ocurrió en 2015, cuando hubo una alza en malformaciones congénitas y otras complicaciones neurológicas. ${ }^{1}$ En Abril del 2016, el Departamento de Estado de los Estados Unidos destinó fondos para una Respuesta al Zika de la USAID, priorizando, en países afectados, esfuerzos programáticos orientados a minimizar los efectos negativos del Zika durante el embarazo.

Un elemento central de la Respuesta al Zika de la USAID son los programas de cambios sociales y de comportamiento, que tienen como objetivo promover prácticas y comportamientos efectivos que reduzcan la transmisión del Zika. Estos programas enfatizan la protección personal para mujeres embarazadas, involucran a comunidades de alto riesgo en prácticas de prevención, y mejoran el acceso de mujeres a servicios de atención prenatal.*

\section{¿Por qué recopilamos información sobre conocimiento, actitudes y prácticas?}

Las teorías de cambio de comportamiento nos ayudan a entender qué factores facilitan y motivan a las personas a comportarse de una manera u otra. ${ }^{4} \mathrm{El}$ modelo socioecológico de cambio de comportamiento destaca la importancia de factores individuales (como el conocimiento, las percepciones y las actitudes sobre una enfermedad y su prevención), factores comunitarios (como el ambiente normativo) y factores sociales y estructurales (como el acceso a recursos y servicios) para entender si una persona realiza o no un comportamiento en particular. Otro modelo-Extended Parallel Processing Model-destaca que la percepción de riesgo que una persona asocia con una enfermedad, como también su confianza en la efectividad de una posible solución y su compromiso con practicarlas, impactará en que una persona realice prácticas preventivas o no. ${ }^{4}$ Esta y otras teorías ofrecen una base para medir indicadores que permiten que ejecutores de programas de cambio social y de comportamiento decidan las mejores estrategias para impactar el comportamiento de comunidades específicas.

\section{¿Cómo se recopilaron los datos?}

En el año 2018, el proyecto Breakthrough RESEARCH realizó una encuesta transversal de hogares en Guatemala, Honduras, El Salvador y la República Dominicana. La encuesta evaluó, entre otros factores, el conocimiento, las actitudes y los comportamientos (CAP) relacionados al Zika y a otras enfermedades transmitidas por el mosquito Aedes aegypti. Se utilizó un diseño muestral aleatorio, multietápico y por conglomerado. Se encuestaron hombres y mujeres de entre

\footnotetext{
* Para mayor información visite:

www.usaid.gov/what-we-do/global-health/zika.
}

\section{¿POR QUÉ IMPORTA EL ZIKA?}

- El virus del Zika es una enfermedad contagiosa transmitida por los mosquitos Aedes aegypti, que también transmiten otros arbovirus, como el dengue y la chikunguña.

- El Zika también se puede transmitir a través de relaciones sexuales y de una madre embarazada a su feto.' Se sabe que el Zika puede causar problemas neurológicos, como el síndrome congénito por el virus del Zika. ${ }^{2,3}$

- Muchas personas infectadas con el virus del Zika no desarrollan síntomas, lo que genera una percepción de riesgo menor. ${ }^{2}$

18 y 49 años, residentes de áreas de intervención de programas de la USAID. En Guatemala, la encuesta fue realizada entre agosto y octubre del 2018 en las áreas de intervención del programa de Respuesta al Zika de la USAID de cuatro provincias: Quetzaltenango, Suchitepequez, Santa Rosa, y Chiquimula. Se entrevistó a 668 personas, de las cuáles 36 por ciento eran hombres y 64 por ciento eran mujeres. Los datos se ponderaron según características sociodemográficas a modo de reflejar la población de las áreas de intervención.

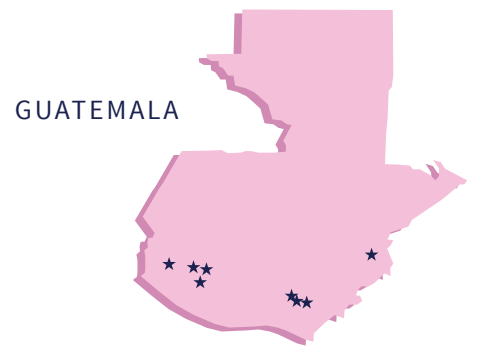

El estudio recogió información sobre cuatro grandes dimensiones:

- Información sociodemográfica: Edad, educación, sexo, bienes del hogar.

- Conocimiento: Transmisión, efectos en la salud, prevención de cada enfermedad.

- Actitudes: Percepciones de riesgo de la enfermedad, efectividad de comportamientos preventivos, factibilidad de llevar a cabo conductas preventivas.

- Autorreporte de conductas preventivas: Comportamientos para prevenir picaduras de mosquitos y criaderos de mosquitos en los últimos siete días y en los últimos treinta días. 


\section{Implicancias programáticas claves}

Estas recomendaciones para programas que impulsen cambios sociales y de comportamiento están basadas en hallazgos de las encuestas realizadas en Guatemala.

1. Los programas y mensajes de prevención debiesen destacar los vínculos entre el virus del Zika y posibles defectos congénitos, incluyendo el síndrome congénito por el virus del Zika, especialmente entre mujeres embarazadas y sus parejas, ya que tener un hijo saludable puede ser una motivación fundamental para prevenir el virus.

2. Los mensajes de prevención debiesen continuar destacando el rol de la transmisión sexual del Zika, especialmente, entre mujeres embarazadas y sus parejas, y enfatizar la importancia del condón para evitar la transmisión del virus durante el embarazo.

3. Los programas de prevención debiesen priorizar comportamientos que cuentan con evidencia de su efectividad contra el Zika; particularmente aquellos comportamientos de prevención personal durante el embarazo que son percibidos como de menor efectividad que otros comportamientos realmente menos efectivos.

4. Los programas de prevención debiesen incluir mensajes que contengan instrucciones detalladas para realizar comportamientos preventivos complejos.

5. Los programas de prevención debiesen especificar que los mosquitos pueden picar a cualquier hora $y$ destacar que las estrategias de protección personal, como el uso de repelentes, se deben llevar a cabo durante el transcurso de todo el día, especialmente entre mujeres embarazadas y sus parejas.

6. Los mensajes de prevención entregados durante visitas domiciliares de control vectorial son una estrategia prometedora para aumentar el conocimiento de las personas y promover conductas preventivas.
- Prácticas observadas: Identificación del uso de tapas seguras para el almacenamiento de agua donde suelen estar los criaderos de mosquitos.

\section{Hallazgos clave sobre el conocimiento del Zika}

\section{Conocimiento de la enfermedad}

La mayoría de las personas encuestadas habían escuchado del Zika, dengue o chikunguña, y por lo menos tres cuartos de las personas habían escuchado sobre las tres enfermedades (ver Tabla 1). Sin embargo, personas de menores ingresos (aquellos del quintil más bajo) tienen un nivel de conocimiento del Zika significativamente más bajo que las personas del quintil más alto (84 por ciento frente a un 97 por ciento, $\mathrm{p}<.001$ ).

\begin{tabular}{|c|c|}
\hline ENFERMEDAD & $\begin{array}{c}\text { \% DE PERSONAS QUE HAN } \\
\text { ESCUCHADO DE LA ENFERMEDAD }\end{array}$ \\
\hline Zika & $91 \%$ \\
\hline Dengue & $95 \%$ \\
\hline Chikunguña & $97 \%$ \\
\hline
\end{tabular}

\section{Mecanismos de transmisión del Zika y sus efectos en la salud}

Mediante mosquitos: Entre quienes respondieron conocer cada enfermedad, casi todos estaban informados de que los mosquitos pueden transmitir Zika (89 por ciento), dengue (96 por ciento) y chikunguña (91 por ciento). Solo un tercio (33 por ciento) de quienes sabían que el Zika se transmite mediante mosquitos, 35 por ciento de quienes sabían que el dengue se transmite mediante mosquitos, y 42 por ciento de quienes sabían que la chikunguña se transmite mediante mosquitos sabía que una picadura puede ocurrir a cualquier hora del día o de la noche.

Mediante contacto sexual y transmisión vertical: Solo 18 por ciento de los encuestados que había escuchado del Zika sabía que se puede transmitir sexualmente y solo 3 por ciento sabía que se puede transmitir de una madre a un feto durante el embarazo.

Solo 22 por ciento de los encuestados que había escuchado del Zika identificó defectos congénitos como un posible efecto adverso del Zika sobre la salud. Los individuos con menos recursos (del quintil más bajo) estaban significativamente

† Se utilizó la prueba de chi-cuadrado para todos los análisis bivariados. 
menos informados acerca de los efectos congénitos del Zika que personas del quintil más alto (16 por ciento frente a un 32 por ciento, $\mathrm{p}<0.05$ ).

\section{Métodos de prevención}

De los participantes que habían escuchado sobre el Zika, un 82 por ciento conocía al menos un método efectivo para prevenir el virus. ${ }^{\ddagger}$

Los métodos de prevención para reducir el riesgo del Zika más mencionados por parte de los encuestados fueron eliminar agua estancada (67 por ciento), limpiar basura cercana a la vivienda que alberga mosquitos (deschatarrización) (41 por ciento), cambiar agua almacenada (28 por ciento) y limpiar recipientes o contenedores de agua (27 por ciento).

Solo 20 por ciento de los participantes identificó el uso de repelentes, 11 por ciento identificó tapar recipientes de agua, y menos de tres por ciento identificó el uso de condones como métodos de prevención.

\section{Hallazgos claves de actitudes sobre el Zika}

\section{Percepciones de riesgo del Zika, dengue y chikunguña}

La gran mayoría de los participantes percibió estar en algún nivel de riesgo de contraer Zika, sea bajo, medio o alto. Pocas personas percibieron no estar a riesgo o no conocer su riesgo de contraer Zika, dengue o chikunguña). Como muestra la Figura 1, casi la mitad de los encuestados percibió estar en una

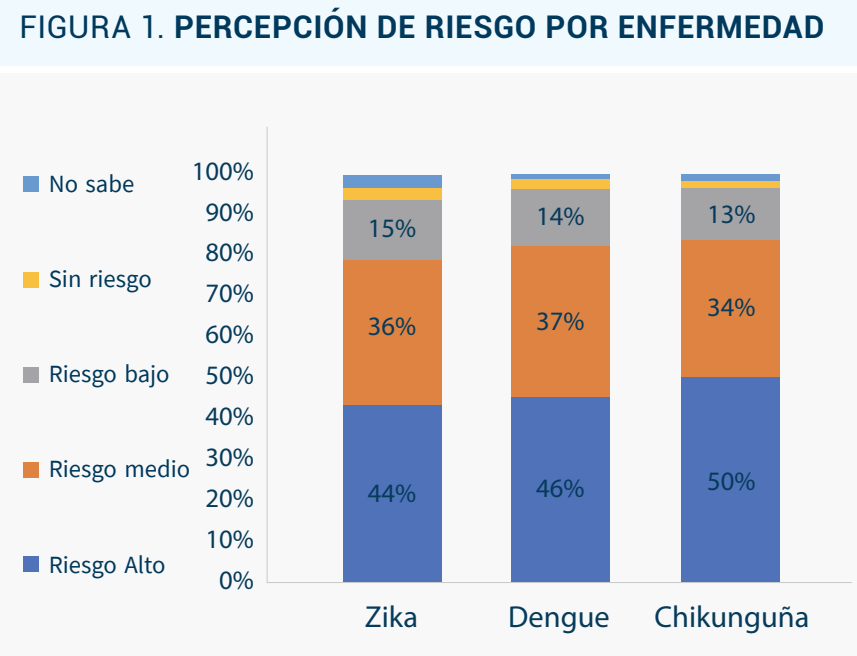

¥ Comportamientos efectivos: Usar repelente, vaciar agua estancada, limpiar recipientes y contenedores de agua, tapar recipientes y contenedores de agua, usar larvicida, usar rejillas en ventanas y puertas. situación de riesgo alta de contraer Zika (44 por ciento), dengue (46 por ciento) o chikunguña (50 por ciento). Aproximadamente un tercio de los participantes respondió estar en un nivel medio de riesgo de contraer Zika (36 por ciento), dengue (37 por ciento) y chikunguña (34 por ciento). Además, la mayoría de los participantes respondió que estarían muy preocupados si llegasen a contagiarse de Zika (80 por ciento), dengue (80 por ciento) o chikunguña (81 por ciento).

\section{Percepciones de factibilidad de conductas preventivas}

Al responder sobre cómo perciben la factibilidad de las conductas preventivas incluidas en la Tabla 2, ninguna de las alternativas fue considerada como muy fácil de llevar a cabo por parte de la mayoría de los encuestados. Menos del 18 por ciento de los participantes del estudio consideró el uso de condones en general y durante el embarazo como algo muy fácil de hacer.

\section{TABLA 2. PORCENTAJE DE ENCUESTADOS QUE PERCIBEN EL SIGUIENTE COMPORTAMIENTO PREVENTIVO COMO "MUY FÁCIL"}

\begin{tabular}{l|c}
\hline COMPORTAMIENTO & $\%$ \\
\hline Usar repelente & $23 \%$ \\
\hline Cambiar agua almacenada intencionalmente & $21 \%$ \\
\hline Limpiar recipientes de agua & $20 \%$ \\
\hline Vaciar agua estancada en el hogar & $20 \%$ \\
\hline Tapar recipientes de agua & $18 \%$ \\
\hline Usar condones en general & $18 \%$ \\
\hline Vaciar agua estancada en la communidad & $17 \%$ \\
\hline Usar condones durante el embarazo & $17 \%$ \\
\hline Usar larvicida & $14 \%$ \\
\hline
\end{tabular}

\section{Percepciones de efectividad de conductas preventivas}

Al enumerar conductas preventivas según su nivel de efectividad para prevenir la crianza de mosquitos y enfermedades como el Zika, 58 por ciento de los participantes consideraron que eliminar agua estancada era el método más efectivo, seguido por el uso de insecticida (45 por ciento) y el uso de mosquiteros (32 por ciento) (ver Tabla 3). 
TABLA 3. PORCENTAJE DE ENCUESTADOS QUE PERCIBEN EL SIGUIENTE COMPORTAMIENTO COMO UNA DE LAS TRES FORMAS MÁS EFECTIVAS PARA PREVENIR EL ZIKA

\begin{tabular}{l|c}
\hline COMPORTAMIENTO & $\%$ \\
\hline Eliminar agua estancada & $58 \%$ \\
\hline Fumigar con insecticida (ej. Raid) & $45 \%$ \\
\hline Usar mosquiteros en las camas & $32 \%$ \\
\hline Despejar basura afuera de la casa & $31 \%$ \\
\hline Usar repelente & $30 \%$ \\
\hline Limpiar recipientes de agua & $16 \%$ \\
\hline Usar espirales repelentes & $13 \%$ \\
\hline Cambiar agua estancada & $12 \%$ \\
\hline Usar condones & $10 \%$ \\
\hline Usar rejillas en ventanas y puertas & $10 \%$ \\
\hline Usar larvicida & $9 \%$ \\
\hline Tapar contenedores o recipientes de agua & $6 \%$ \\
\hline
\end{tabular}

\section{Hallazgos clave sobre comportamientos preventivos}

\section{Prácticas para prevenir la transmisión sexual del Zika}

Si bien más de un sexto (16 por ciento) de los encuestados utilizó condones durante algún encuentro sexual en los últimos treinta días, solo el uno por ciento respondió haberlos usado para prevenir el Zika.

\section{Prácticas para prevenir picaduras de mosquitos y criaderos de mosquitos}

De las personas encuestadas:

- 77 por ciento respondió haber hecho algo para prevenir picaduras de mosquito en los últimos treinta días, pero solo 71 por ciento declara haber llevado a cabo al menos una práctica preventiva de alta efectividad en ese tiempo.

- 70 por ciento respondió haber hecho algo para prevenir picaduras de mosquito en los últimos siete días, pero solo 58 por ciento declara haber llevado a cabo al menos una práctica preventiva de alta efectividad en ese tiempo.
Según las respuestas a una pregunta abierta, la Figura 2 muestra los comportamientos preventivos más frecuentes realizados en los últimos 30 días y últimos 7 días. El más reportado fue usar mosquiteros, mientras que el menos frecuente fue acciones comunitarias para remover agua acumulada. Los comportamientos preventivos de mayor efectividad están marcados con un asterisco.

\section{FIGURA 2. COMPORTAMIENTOS PREVENTIVOS EN LOS ÚLTIMOS 30 Y 7 DÍAS}

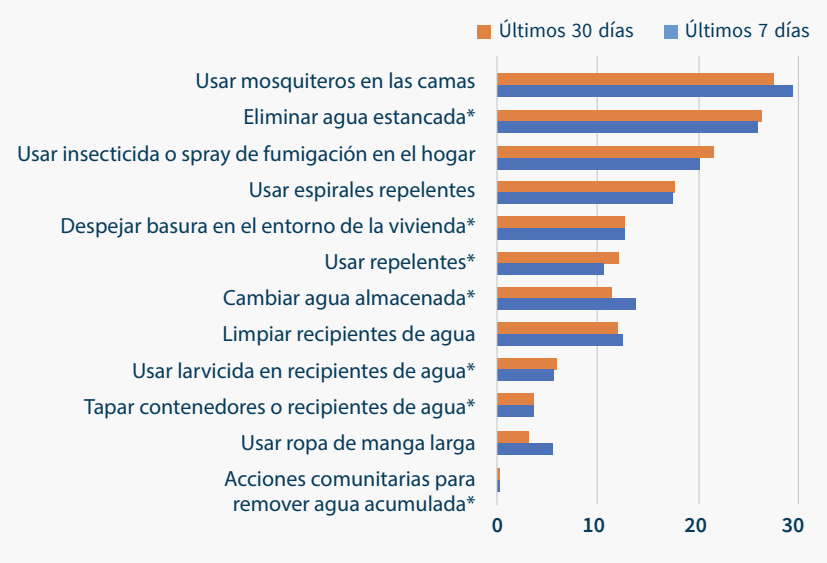

Casi un cuarto (23 por ciento) de las personas encuestadas respondió no haber llevado a cabo ningún tipo de conducta preventiva en los últimos 30 días. Estar muy ocupado (38 por ciento) y considerar que requieren mucho esfuerzo (15 por ciento) fueron los motivos más mencionados por los participantes para explicar la baja cantidad de conductas preventivas realizadas.

Respecto al uso de repelente, la barrera más común para su uso fue su costo (24 por ciento) y falta de materiales (32 por ciento).

\section{Prácticas relacionadas con recipientes de agua}

Para entender la manera en que las personas en Guatemala limpian sus recipientes o contenedores de agua, se les pidió a quienes lo habían hecho en los últimos siete días que especificaran cada paso que llevaron a cabo. La Tabla 4 muestra las acciones reportadas para limpiar recipientes de agua. Más de la mitad de quienes respondieron a esta pregunta (65 por ciento) reportaron haber cepillado las paredes del recipiente y aplicado detergente a las paredes del recipiente (57 por ciento). Además, 57 por ciento de las personas le agregaron cloro al agua, un método de baja efectividad para eliminar mosquitos o larvas de mosquito. Casi la mitad de los encuestados (45 por ciento) respondieron haber vaciado el recipiente como un paso previo a limpiarlo. Un tercio (33 por ciento) señaló haberles aplicado cloro a las paredes del recipiente y un cuarto (23 por ciento) declaró haber enjuagado el recipiente. Solo 13 por ciento de los participantes respondió haber esperado algunos minutos para dejar actuar los productos de limpieza en la superficie del recipiente de agua. 
TABLA 4. PORCENTAJE DE ENCUESTADOS QUE LIMPIARON SU RECIPIENTE O CONTENEDOR DE AGUA CON LA SIGUIENTE ACCIÓN

\begin{tabular}{l|c}
\hline ACCIONES & $\%$ \\
\hline Cepillar el recipiente & $65 \%$ \\
\hline Aplicar detergente a las paredes del recipiente & $57 \%$ \\
\hline Agregarle cloro al agua & $55 \%$ \\
\hline Vaciar el recipiente & $45 \%$ \\
\hline Aplicar cloro a las paredes del recipiente & $33 \%$ \\
\hline Enjuagar el recipiente & $23 \%$ \\
\hline $\begin{array}{l}\text { Dejar que los productos de limpieza hagan } \\
\text { efecto durante algunos minutos }\end{array}$ & $13 \%$ \\
\hline
\end{tabular}

Además de la encuesta, también se recogieron datos mediante la observación de recipientes o contenedores de agua en las casas de los participantes. 582 de los encuestados en Guatemala (87 por ciento) accedió a que un encuestador observara los recipientes o contenedores de agua de su hogar. Del total, 662 de los contenedores observados fueron pilas y 332 fueron recipientes de agua de largo plazo. Los encuestadores observaron las tapas de los recipientes para evaluar su calidad. Para tapar un recipiente de manera efectiva, las tapas deben cubrir completamente el recipiente y encajar bien, evitando cualquier espacio abierto en toda la circunferencia; si el material de la tapa es plástico sólido, no debe estar doblado ni debe permitir que el agua se acumule en su superficie; si el material de la tapa es maleable, no debe tocar la superficie del agua para no arriesgar la formación de criaderos de mosquitos adicionales.

En total, se hallaron larvas de mosquito en 17 por ciento de las pilas y 29 por ciento de los recipientes o contenedores de largo plazo. No se encontraron diferencias significativas entre las pilas que estaban tapadas de manera correcta y las que no. En contraste, era significativamente menos probable que recipientes de largo plazo que estaban tapados de manera correcta tuvieran larvas de mosquito, frente a aquellos tapados de manera incorrecta (recipientes que no estaban cubiertos o cuya tapa no cumplía con criterios de eficiencia en cobertura). En solo uno por ciento de los recipientes de largo plazo cubiertos de manera correcta se encontraron larvas, frente a un 41 por ciento entre recipientes tapados de manera incorrecta $(p<0.001)$. Esta diferencia se mantiene incluso al controlar por el autorreporte de limpieza de los recipientes en los últimos treinta días.
Asociaciones entre determinantes de comportamiento y comportamientos preventivos§

En Guatemala, el principal predictor para realizar comportamientos que prevengan la picadura y reproducción de mosquitos es tener conocimiento sobre comportamientos preventivos efectivos. Un mayor conocimiento de comportamientos preventivos efectivos estaba relacionado significativamente con un mayor autorreporte de los siguientes comportamientos: tapar recipientes de agua $(p<0.001)$ limpiar agua estancada $(p<0.001)$, y limpiar recipientes de agua $(p<0.001)$. Las personas con un buen conocimiento del Zika -que conocían ocho o más comportamientos preventivostenían aproximadamente tres veces más probabilidades (87 por ciento frente a un 24 por ciento) de realizar comportamientos preventivos que aquellas que no.

Las visitas a hogares estaban correlacionadas significativamente con un mayor autorreporte de haber cepillado y limpiado recipientes de agua. Las personas que recibieron en su hogar a voluntarios o técnicos entrenados en prevención para hablar sobre cómo prevenir mosquitos en su vivienda tuvieron mayor probabilidad de haber limpiado (diferencia de 14\%, p<0.05) y de haberlo tapado ( diferencia de $7 \%, p<0.05)$. No se encontraron asociaciones significativas entre visita a hogares y los siguientes comportamientos: eliminar agua estancada y usar repelente.

La efectividad percibida de un comportamiento preventivo estaba significativamente relacionada con su realización. Las personas que consideraron que usar repelentes o limpiar recipientes agua estancada eran de los tres métodos más efectivos para prevenir la transmisión del Zika mediante mosquitos tenían, respectivamente, un 10 por ciento y 9 por ciento mayor de probabilidad de haber realizado dicha acción en los últimos treinta días $(p<0.01)$.

\section{Conclusiones e implicancias para el futuro}

En las áreas de Guatemala que fueron estudiadas, la gran mayoría de la población ha escuchado acerca del virus del Zika, y casi todos quienes conocen el virus saben que se transmite mediante mosquitos. No obstante, solo un tercio de las personas que saben que el Zika se transmite mediante mosquitos están informadas de que las picaduras pueden ocurrir a cualquier hora del día o la noche. Los mensajes que formen parte de programas de prevención deben continuar destacando la necesidad de proteger a la población -y especialmente a las mujeres embarazadas- de picaduras de mosquito a cualquier hora del día. ${ }^{7}$ Además, pocas personas son conscientes de que

$\S$ Los resultados de esta sección están basados en análisis de regresión logística. 
el virus se puede transmitir mediante relaciones sexuales, y se sabe poco de los efectos adversos en salud que puede generar el Zika durante el embarazo. Si bien se estima que solo entre cuatro y cinco por ciento de las transmisiones de Zika ocurren mediante relaciones sexuales, las implicancias de la transmisión del Zika durante el embarazo son tan graves que los programas deben continuar educando sobre la transmisión sexual del Zika como también sobre sus posibles consecuencias durante el embarazo, especialmente a mujeres embarazadas y sus parejas. ${ }^{5,6}$

El único comportamiento preventivo de control del vector altamente conocido entre la mayoría de los encuestados es eliminar agua estancada. Un bajo porcentaje de los participantes era capaz nombrar otro mecanismo de prevención, especialmente alguno de protección personal, como el uso de condones o repelentes. Las personas en general no están informadas del uso del condón como mecanismo de prevención ante el Zika. Además, los comportamientos preventivos de mayor efectividad eran practicados con menor frecuencia que comportamientos menos efectivos, como el uso de mosquiteros en las camas. Los programas de prevención deben continuar destacando los distintos comportamientos que ayudan a prevenir el Zika, especialmente aquellos de protección personal que son de particular importancia durante el embarazo. Los mensajes deben incluir instrucciones detalladas que expliquen los comportamientos de mayor complejidad. 7,8 Para que comportamientos preventivos de control vector (como escobillar recipientes de agua o tapar recipientes de manera correcta) sean efectivos en eliminar mosquitos, es de suma importancia no saltarse ningún paso.

Finalmente, las visitas presenciales a los hogares siguen siendo un mecanismo favorable para estimular e informar a poblaciones en situaciones de alto riesgo y promover prácticas preventivas. Los especialistas que visiten hogares pueden destacar con mayor énfasis los comportamientos preventivos de protección personal, para que lleguen a ser igualmente conocidos que los comportamientos preventivos de control vector. 


\section{Referencias bibliográficas}

1 World Health Organization (WHO). 2016. Zika Strategic Response Plan. Geneva, Switzerland: WHO.

2 Haby, Michelle M. et al. 2018. "Prevalence of asymptomatic Zika virus infection: a systematic review," Bulletin of the World Health Organization 96: 402-413D.

3 Centers for Disease Control and Prevention (CDC). 2018. Congenital Zika Syndrome \& Other Birth Defects. Atlanta: CDC. Available from www.cdc.gov/pregnancy/ zika/testing-follow-up/zika-syndrome-birth-defects. html.

4 Health Communication Capacity Collaborative. 2016. Social and Behavior Change Communication for Emergency Preparedness Implementation Kit. Baltimore: Johns Hopkins University (JHU). Available from: http://healthcommcapacity.org/wp-content/ uploads/2017/01/SBCCforEP l-Kit.pdf.

5 Coelho, Flavio Codeco et al. 2016. "Higher incidence of Zika in adult women than adult men in Rio de Janeiro suggests a significant contribution of sexual transmission from men to women," International Journal of Infectious Diseases 51: 128-132.

6 Rao, Rashmi et al. 2017. "Zika risk and pregnancy in clinical practice: ongoing experience as the outbreak evolves," Obstetrics and Gynecology 129(6): 10981103

7 Breakthrough ACTION+RESEARCH. 2018. Zika Prevention Behavior Matrix. Baltimore: JHU. Available from www.zikacommunicationnetwork.org/resources/ zika-prevention-behavior-matrix.

8 Breakthrough ACTION+RESEARCH. 2018. Technical Specification Content Guide for Behaviors With a High Potential to Prevent Zika. Baltimore: JHU. Available from www.zikacommunicationnetwork.org/resources/ technical-specifications-content-guide-behaviors-highpotential-prevent-zika.

\section{Agradecimientos}

Este informe de investigación describe el trabajo liderado por la Universidad de Tulane bajo el Proyecto Breakthrough RESEARCH, en colaboración con TEPHINET en Guatemala. Este informe fue desarrollado por Martha Silva y Julia Fleckman de la Universidad de Tulane, junto a Kate Spielman del Population Council. Paul Hewett del Population Council y Arianna Serino de la Agencia para el Desarrollo Internacional de los Estados Unidos (The United States Agency for International Development - USAID) sirvieron de revisores técnicos. Heidi Worley de PRB apoyó el trabajo editorial y Katie Hoch realizó el diseño gráfico. Cristián Valenzuela tradujo el texto al español.

\section{Cita sugerida:}

Silva, M., J. Fleckman, and K. Spielman. "Conocimiento, Actitudes y Prácticas sobre el Zika: Implicancias Programáticas para Prevención del Zika en Guatemala," Breakthrough Research Consortium Programmatic Research Brief (Julio 2019). Washington, DC: Population Council.

\section{Crédito fotográfico:}

MarcPo, Getty Images

(C) 2019 The Population Council. Todos los derechos reservados.

\section{Breakthrough RESEARCH, Population Council}

4301 Connecticut Ave., NW, Suite 280 | Washington, DC 20008 +12022379400 | breakthroughactionandresearch.org

BreakthroughRESEARCH@popcouncil.org

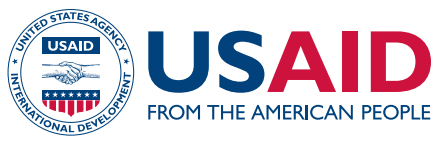

Breakthrough RESEARCH is made possible by the generous support of the American people through the United States Agency for International Development (USAID) under the terms of cooperative agreement no. AIDOAA-A-17-00018. The contents of this document are the sole responsibility of the Breakthrough RESEARCH and Population Council and do not necessarily reflect the views of USAID or the United States Government.

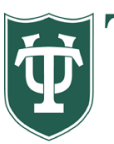

Tulane University

POPULATION COUNCIL

Ideas. Evidence. Impact.

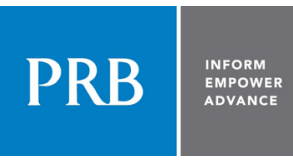

\section{Breakthrough RESEARCH FOR SOCIAL \& BEHAVIOR CHANGE

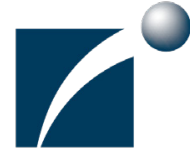

Breakthrough RESEARCH catalyzes social and behavior change (SBC) by conducting state-ofthe-art research and evaluation and promoting evidence-based solutions to improve health and development programs around the world. Breakthrough RESEARCH is a consortium led by the Population Council in partnership with Avenir Health, ideas42, Institute for Reproductive Health at Georgetown University, Population Reference Bureau, and Tulane University. 